\title{
Erectile dysfunction in common neurological conditions: A narrative review
}

\author{
Mohamad Moussa ${ }^{1}$, Athanasios G. Papatsoris ${ }^{2}$, Mohamed Abou Chakra ${ }^{3}$, Baraa Dabboucy ${ }^{4}$, \\ Youssef Fares ${ }^{5}$ \\ ${ }^{1}$ Urology Department, Zahraa Hospital, University Medical Center, Beirut, Lebanon; \\ $22^{\text {nd }}$ Department of Urology, School of Medicine, Sismanoglio Hospital, National and Kapodistrian University of Athens, \\ Athens, Greece: \\ ${ }^{3}$ Department of Urology, Faculty of Medical Sciences, Lebanese University, Beirut, Lebanon; \\ ${ }^{4}$ Department of Neurosurgery, Faculty of Medical Sciences, Lebanese University, Beirut, Lebanon; \\ ${ }^{5}$ Department of Neurosurgery, Neuroscience Research Center, Faculty of Medical Sciences, Lebanese University, Beirut, Lebanon.
}

\begin{abstract}
Summary Neurogenic erectile dysfunction (NED) can be defined as the inability to achieve or maintain an erection due to central or peripheral neurologic disease. Neurologic diseases can also affect the physical ability and psychological status of the patient. All these factors may lead to a primary or secondary NED. Medication history plays an important role since there are many drugs commonly used in neurologic patients that can lead to ED. The assessment of NED in these patients is generally evolving with the application of evoked potentials technology in the test of somatic and autonomic nerves, and functional magnetic resonance imaging With the electrophysiological examinations, neurogenic causes can be determined. These tools allow to categorize neurologic lesion and assess the patient prognosis. The first-line treatment for NED is phosphodiesterase inhibitors. Second-line treatments include intracavernous and intraurethral vasoactive injections. Third-line treatments are penile prostheses. The efficacy and safety of each treatment modality depend on the specific neurologic condition. This review discusses the physiology, pathophysiology, diagnosis, and treatment of ED in multiple peripheral and central neurologic conditions, as well as for future research.
\end{abstract}

KEY WORDS: Erectile dysfunction, Neurogenic, Neurologic disability, Management.

Submitted 19 May 2020; Accepted 6 August 2020

\section{INTRODUCTION}

Erectile dysfunction (ED) is common (affecting 10-20 million men in the USA) and multifactorial disease due to organic and/or psychological factors that strongly impair the quality of life in man. During the past decade, many advances in the understanding of the pathophysiology of ED have been made and new therapeutic strategies have become available (1). ED is the inability to achieve or maintain an erection that is sufficient for satisfactory sexual performance and affects a considerable proportion of men at least occasionally. The severity of ED is often described as mild, moderate or severe according to the five-item International Index of Erectile Function (IIEF-5) questionnaire, with a score of 1-7 indicating severe ED,
8-11 moderate ED, 12-16 mild-moderate ED, 17-21 mild ED and 22-25 no ED (2). Risk factors for ED are numerous, with patients over 40 years old demonstrating a significant association between ED and cardiovascular risk factors including hypertension, dyslipidemia, diabetes mellitus (DM), coronary artery disease, and the metabolic syndrome (3). Organic causes are responsible for about $60 \%$ to $90 \%$ of all causes of ED. Most frequent pathologies involved are vasculogenic. The most common etiologies are due to low blood inflow (large vessel atherosclerosis), DM, endocrinologic disorders, neurogenic, trauma, penile disease, iatrogenic, and drugs. It was estimated that $10-19 \%$ of the organic ED are neurogenic. The main causes are intracerebral (Parkinson's disease, cerebrovascular disease, stroke, encephalitis, or temporal lobe epilepsy) or spinal cord etiologies (trauma, multiple sclerosis, myelodysplasia). Peripheral nerves are also affected in alcoholic neuropathy, diabetic neuropathy, after surgery (radical pelvic surgery), and trauma (4). The first distinction of ED that should be established is psychogenic from organic.

Clues to suggest a psychogenic etiology include sudden onset, good quality spontaneous or self-stimulated erections, major life events, or previous psychological problems. Conversely, gradual onset, lack of tumescence, and normal libido are more suggestive of an organic etiology (5). Identification of ED can be made through questionnaires or a complete medical and sexual history. Anamnesis and laboratory tests are sufficient in most cases to identify ED and to manage the treatment.

Supplementary tests are used in special cases or where confirmation of an etiological diagnosis is required (6).

The current standard of care for ED consists of lifestyle changes such as management of diet, diabetes, hypertension, and weight loss, along with pharmacotherapies. The current gold standard treatment is the use of phosphodiesterase 5 inhibitors (PDE5i) (7). PDE5i are the most effective oral drugs for the treatment of ED, including ED associated with DM, spinal cord injury, and antidepressants. Intraurethral and intracavernosal injections (ICI), vacuum pump devices, and surgically implanted penile prostheses are alternative therapeutic options

No conflict of interest declared. 
when PDE5i fail. Testosterone supplementation in men with hypogonadism improves ED and libido (8).

More invasive options exist for patients who do not respond to PDE-5 i therapy or in whom it is contraindicated. Alprostadil (prostaglandin E1) causes smoothmuscle relaxation and subsequent vasodilation by acting on adenylate cyclase to increase the intracellular cyclic adenosine monophosphate (cAMP) concentration.

Prostaglandin E1 may be administered intraurethrally, where it is absorbed and transported throughout the erectile bodies. Vasoactive drugs may also be injected intracavernosally. Such therapy represents an important second-line therapy for ED. It is the most effective pharmacologic treatment but has a high dropout rate because of the associated pain (9). Penile prostheses are the only surgical therapy option maintaining its significance as a cure for ED. There are convincing long-term results with a high degree of patient and partner satisfaction, high patient acceptance, and good functional durability of the mostly three-piece inflatable devices (10).

In patients where pharmacological therapy is unhelpful or contraindicated, another option is the surgical approach. Penile vascular surgery is suitable only for healthy men with acquired ED due to isolated stenosis of extra-penile arteries without any kind of generalized vascular disease. Penile prosthesis implant is recognized, at present, as the most effective option to obtain an artificial erection satisfactory for sexual intercourse in those patients in which the pharmacological approach is contraindicated or ineffective (11). We performed a narrative review to discuss the physiology, pathophysiology, diagnosis, and treatment of ED in multiple peripheral and central neurologic conditions. We also presented the novel therapies for ED in some neurologic diseases.

\section{MATERIALS AND METHODS}

We searched electronic databases including PubMed, the Scopus database for published studies that analyzed the role of the following Medical Subject Headings terms: Erectile dysfunction (OR) 'sexual dysfunction' (OR) 'Erection' (OR) 'Neural control' (AND) 'Erection' (OR) 'Electrodiagnostic test' (AND) 'Erectile Dysfunction' (OR) 'Spinal cord injury', 'Cerebrovascular accident', 'Parkinson's disease', 'Multiple sclerosis', 'Epilepsy', 'Herniated disc', 'Multiple system atrophy', 'Peripheral neuropathy' (AND) 'Erectile Dysfunction' (OR) 'Neurogenic Erectile dysfunction'(AND) 'Management'. This was done in order to ensure the comprehensive inclusion of articles related to neurogenic erectile dysfunction. The initial search resulted in 230 articles. After review, we initially excluded papers that were not relevant (85). At completion of review, articles were selected based on their clinical relevance related to the aim. Data extraction was performed by three authors (AP, MM, MA).

\section{Neurogenic erectile dysfunction overview}

Neural control of erection

Erectile function requires the participation of autonomic and somatic nerves (sacral parasympathetic [pelvic], tho- racolumbar sympathetic [hypogastric and lumbar chain], and somatic [pudendal] nerves), with the hypothalamic and limbic pathways playing significant roles.

Neurologic diseases can also challenge the physical ability of the individual to embrace, stimulate, engage in intercourse, and maintain urinary and bowel continence during sexual activity. All these factors may lead to a primary or secondary neurogenic ED (12).

From the neurons in the spinal cord and peripheral ganglia, the sympathetic and parasympathetic nerves merge to form the cavernous nerve. The somatic nerves are primarily responsible for sensation and the contraction of the bulbocavernosus and ischiocavernosus muscles. The sympathetic pathway originates from the $11^{\text {th }}$ thoracic to the $2^{\text {nd }}$ lumbar spinal segments and passes through the white rami to the sympathetic chain ganglia. The parasympathetic pathway arises from neurons in the intermediolateral cell columns of the second, third, and fourth sacral spinal cord segments. The preganglionic fibers pass in the pelvic nerves to the pelvic plexus. The cavernous nerves are branches of the pelvic plexus that innervate the penis. No psychogenic erection occurs in patients with lesions above T9; the efferent sympathetic outflow is thus suggested to be at the levels T11 and T12 (13).

Sensory information from the genitals is a potent activator of pro-erectile spinal neurons and elicits reflexive erections. Some pre-motor neurons of the medulla, pons and diencephalon project directly onto spinal sympathetic, parasympathetic, and pudendal motoneurons. They receive in turn sensory information from the genitals (14). The somatic sensory and motor innervation of the male genitalia is carried via branches of the pudendal nerve. The pudendal nerve arises from sacral spinal segments 2-4 $\left(\mathrm{S}_{2}-\mathrm{S}_{4}\right)$. There are three branches of the pudendal nerve (dorsal nerve of the penis, perineal and inferior rectal), each carrying sensory input to the $S_{2}-S_{4}$ spinal levels from the genital structures, which is relayed through the central nervous system via ascending spinal tracts. The skeletal pelvic floor muscles receive somatic innervation mainly from the motor branches of the pudendal nerve (15).

Penile erection can be elicited by various stimuli integrated into the spinal cord and/or higher central nervous structures. The medial preoptic area (MPOA) of the hypothalamus is known to play a key role in the regulation of male sexual behavior (16). Spinal erectile centers may be activated by genital afferents or by descending commands from higher central sites. An important inhibitory pathway from the nucleus paragigantocellularis has been demonstrated. The MPOA has been demonstrated to be crucially involved in sexual behavior. It is likely that it participates in the integration of hormonal and sensory cues necessary for sexual behavior. The medial amygdala and paraventricular nucleus of the hypothalamus have also been shown to play key roles (17).

Centrally as well as peripherally, many transmitters and transmitter systems are involved. Dopamine, nitric oxide, oxytocin, and ACTH/alpha-MSH, seem to have a facilitatory role, whereas serotonin may be either facilitatory or inhibitory, and enkephalins are inhibitory. Peripherally, the balance between contractant (noradrenaline, endothelins, angiotensins) and relaxant (NO, VIP, 
and related peptides, prostanoids) factors controls the degree of contraction of the smooth muscle of the corpora cavernosa and determines the functional state of the penis (18).

Psychogenic erection is a result of audiovisual stimuli or fantasy. Impulses from the brain modulate the spinal erection centers $\left(T_{11}-L_{2}\right.$ and $\left.S_{2}-S_{4}\right)$ to activate the erectile process. Reflexogenic erection is produced by tactile stimuli to the genital organs. The impulses reach the spinal erection centers; some then follow the ascending tract, resulting in sensory perception, while others activate the autonomic nuclei to send messages via the cavernous nerves to the penis to induce erection. This type of erection is preserved in patients with upper spinal cord injury. Nocturnal erection occurs mostly during rapid-eye-movement (REM) sleep (13).

\section{Electrodiagnostic test of genital nerves}

The sympathetic skin response (SSR) tests have been applied to evaluate the autonomic innervation of the genital skin. SSR are helpful in the evaluation of sexual impotence and of disorders affecting the pelvic floor as well as of well-known neuropathies (19). The SSR was useful as an indicator of the effect on efferent $C$ fibers. Despite SSR being a polysynaptic potential of long latency and regulated by the cerebral cortex, the present results show that it is advisable to record the latencies of SSR in the penis, where it seems to be more useful as a marker of lumbosacral and/or pudendal alterations (20). Corpus cavernosum electromyography (CCE) has been widely done to evaluate autonomic dysfunction in patients with ED. Due to false-negative results on CCE and penile SSR testing evoked cavernous activity (ECA) seems more reliable for determining autonomic involvement in the pathophysiology of ED (21). ECA can be recorded following a brief, startling stimulus. The noxious stimulus results in a generalized, sympathetic nervous system discharge that manifests throughout the body, including the corpus cavernosum. When the discharge is carried through the cavernous nerves, it can be recorded in the corpora cavernosa. If the sympathetic innervation to the corpus cavernosum is disrupted, then ECA will not be present following the startling stimulus (22).

In the last decade, several investigators have tried to develop corpus cavernosum electromyography (CC-EMG) as a direct clinical method to evaluate the state of the penile autonomic innervation and the cavernous smooth muscle. Both basic and clinical studies have shown promising results. However, its application as a diagnostic tool with clinical relevance was hindered by insufficient knowledge of cavernous smooth muscle electrophysiology, lack of standardization, technical and practical difficulties (23).

\section{Erectile dysfunction (ED) in patients with spinal cord injury}

Spinal cord injury (SCI) is not as common as many other injuries, yet its physical and psychosocial consequences are devastating. Very few people experience complete neurologic recovery after SCI. The most common etiologies of SCI were automobile crashes (31.5\%) and falls (25.3\%), followed by gunshot wounds (10.4\%), motor- cycle crashes (6.8\%), diving incidents (4.7\%), and medical/surgical complications (4.3\%) (24).

SCI causes organic changes in men leading to ED, impaired ejaculation, and changes in genital orgasmic perception. A vast majority of men with both complete and incomplete SCI will require treatment for ED (25).

The effect of SCI on the sexual response depends on the level and severity of the injury, as well as personal attributes. The level and completeness of SCI are major determinants of sexual functioning. In the immediate postinjury period, both men and women lose the ability to have reflexive sexual responses. Once reflexes return, reflexive arousal in men can be achieved with genital stimulation if the sacral spinal segments and peripheral pathway conveying sensations (cauda equina) are intact. However, these reflexive responses are usually short-lived, limited to the duration of stimulation, and often do not achieve a fully satisfactory response. If the injury is caudal to the $12^{\text {th }}$ thoracic cord segment men can be expected to experience psychogenic arousal in response to visual, auditory, imaginative, tactile, and gustatory stimuli (26). Sacral sparing refers to the preservation of sensory and/or motor function at the S4-S5 sacral segments and is used to refer to an incomplete SCI; complete SCI do not exhibit sacral sparing. One hundred percent of the men retained reflexogenic erections when the complete lesion was above the sacral segments. Subjects with injury to the conus medularis and cauda equina were able to generate erections using psychogenic and reflexogenic stimuli in $90 \%$ and $80 \%$ of cases, respectively. The production of reflexogenic erections in this group is likely because lesions to the conus medularis or cauda equina are often partial. Lesions below T11 generally only allow filling of the corpora cavernosa via reflexogenic erections (27).

There are social and clinical factors associated with sexual dysfunction (SD) in men with traumatic SCI, as well as predictive factors for SD. Fixed partner, ejaculation, masturbation are protective factors for SD. ED, orgasmic, and infrequent sex dysfunction are predictors of SD (28). For most men with SCI, the basic mechanisms for erection are preserved, including normal vasculature and an intact S2-4 reflex arc. They are often able to have reflex erections, but not psychogenic erections. These men typically respond well to pharmacological treatments used for the management of ED in men without SCI, namely oral PDE-5i such as sildenafil, vardenafil, and tadalafil (29).

Recommendations for the management of ED in SCI men, if it is possible to obtain a satisfactory erection but of insufficient duration, use a venous constrictor band to find out if this is sufficient to maintain the erection. Otherwise, it is recommended to use Sildenafil. If Sildenafil is not satisfactory then use ICI with prostaglandin E (30).

Sildenafil seems more effective in the treatment of neurogenic ED secondary to upper motor neuron (UMN) SCI compared with that secondary to lower motor neuron (LMN) injury. Its efficacy on LMN injuries does not seem different from placebo and administration of this treatment may not be effective in SCI which has caused LMN symptoms (31). A review was conducted to assess the efficacy and safety of sildenafil treatment of ED in men with SCI. As for the general efficacy, the proportion of 
patients who reported improved erections and ability to have intercourse was as high as 94\%. Up to $72 \%$ of intercourse attempts were successful. For measures of erectile function, 5 of the 6 studies showed statistically significant improvements among sildenafil-treated versus placebo-treated patients. Erectile response rates were generally higher in patients with incomplete versus complete SCI and patients with UMN versus LMN lesions (32). A post hoc analysis of pooled data from two randomized, controlled trials (RCT) of sildenafil was conducted in Europe, Australia, and Turkey. It was found that all International Index of Erectile Function outcomes, including achieving and maintaining erections and ejaculation frequency, were statistically significantly greater with sildenafil vs. placebo, including the subgroup with complete SCI ( $p<.01$ for all comparisons). The percentage of successful intercourse attempts with sildenafil (53\% vs $12 \%$ ) and preference for sildenafil (96\% vs. $4 \%$ ) vs. placebo were significant $(\mathrm{p}<.001)$, including the subgroup with complete SCI (33).

A RCT was implemented to assess the efficacy of sildenafil in men with ED associated with complete or incomplete $\mathrm{SCI}$ and to assess its effects on quality of life (QoL). Results showed that compared with placebo, sildenafil produced higher levels of successful sexual stimulation, intercourse success, satisfaction with sexual life and sexual relationship, erectile function, overall sexual satisfaction, and an improved Erectile Dysfunction Inventory of Treatment Satisfaction score, with no clinically relevant effects on vital signs. Sildenafil seemed more effective in patients with incomplete SCI than in those with complete SCI (34). Another study was done by Giuliano et al. to assess the efficacy and safety of oral sildenafil in men with ED caused by traumatic SCI. A total of 178 men received placebo or sildenafil 1 hour before sexual activity for 6 weeks. The 50-mg starting dose could be adjusted to 100 or $25 \mathrm{mg}$ based on efficacy and tolerability. Of 143 men with residual erectile function at baseline, 111 (78\%) reported improved erections and preferred sildenafil to placebo. For all men (including those who reported no residual erectile function at baseline), 127 of
168 (76\%) reported improved erections and preferred sildenafil to placebo (35). A study done by Gans et al. reported that there was significant improvement in quality of erection $(\mathrm{p}<.05)$ if sildenafil used in SCI patients, but no change in satisfaction (36).

Another study was done determine the efficacy and safety of tadalafil when taken on demand by men with ED secondary to SCI. It conclude that tadalafil $(10 \mathrm{mg}$ and $20 \mathrm{mg}$ ) improved erectile function and was well tolerated by men with ED secondary to traumatic SCI. The 2 most common treatment-emergent adverse events in the tadalafil group compared with placebo were headache $(8.5 \%$ vs. $4.5 \%)$ and urinary tract infection $(7.7 \%$ vs. 6.8\%) (37).

Del Popolo et al. compared the safety, time/duration effectiveness, and the impact on the QoL of tadalafil $10 \mathrm{mg}$ vs. sildenafil $50 \mathrm{mg}$ in the treatment of ED in SCI patients. Tadalafil allowed a majority of men in their trial to achieve both normal sexual functioning up to $24 \mathrm{~h}$ postdosing compared to sildenafil $(\mathrm{p}<0.01)$ and improved overall sex life satisfaction as well as sexual relations with a partner (38). Soler et al. compared the efficacy and safety of sildenafil (Viagra), tadalafil (Cialis) and vardenafil (Levitra) for ED in SCI patients. PDE5i were effective in $85 \%$ of the patients on sildenafil, $74 \%$ of the patients on vardenafil, and $72 \%$ of the patients on tadalafil. The mean duration of erection was 34,28 , and $26 \mathrm{~min}$, respectively. Adverse effects were mild, usually attenuated with continued dosing. More than $70 \%$ of the patients on vardenafil and tadalafil required higher doses of $20 \mathrm{mg}$, whereas $50 \mathrm{mg}$ of sildenafil was effective in $55 \%$ of the patients. Their data indicate that sildenafil is more effective in treating ED in SCI patients (39). Studies have shown improvements in erectile function based on IIEF score compared to placebo when PDE5i used in the treatment of ED in patients with SCI, results are summarized in Table 1 (31, 34-41).

Sánchez Ramos et al. reported that sildenafil is an effective, well-tolerated treatment for ED caused by SCI, regardless of the cause, neurological level, American Spinal Injury Association (ASIA) grade, and time since

\section{Table 1.}

Clinical trials testing the efficacy of PDE5i to treat ED in patients with SCI.

\begin{tabular}{|c|c|c|c|}
\hline Authors & N. of patients & Treatment & Main results \\
\hline Khorrami et al. (31) & 105 & 50-100 mg sildenafil vs. placebo & Sildenafil was effective in $82 \%$ of patients UMN disease and its efficacy was statistically higher than placebo ( 82 vs. $25 \%, p<0.05)$ \\
\hline Ergin et al. (34) & 50 & 50-100 mg sildenafil vs. placebo & Sildenafil produced higher levels of successful sexual stimulation, intercourse success, erectile function, vs. placebo \\
\hline Gans et al. (36) & 17 & Sildenafil $25 \mathrm{mg}$ increased by $25 \mathrm{mg}$ as needed & $\begin{array}{l}\text { Erectile function significantly improved }(p<.05) \text { after } 5.3+/-2.2 \text { months when compared with baseline or previous therapies } \\
(p<.05)\end{array}$ \\
\hline Del Popolo et al. (38) & 28 & Tadalafil $10 \mathrm{mg}$ vs. sildenafil $50 \mathrm{mg}$ & Tadalafil $10 \mathrm{mg}$ significantly increased the percentage of successful intercourse attempts at 12-24 hours compared with sildenafil \\
\hline Soler et al. (39) & 240 & $\begin{array}{l}50 \text { to } 100 \mathrm{mg} \text { for sildenafil, from } 10 \\
\text { to } 20 \mathrm{mg} \text { for vardenafil and tadalafil }\end{array}$ & $\begin{array}{l}\text { PDE5 inhibitors were effective (rigidity enough for penetration) in } 85 \% \text { of the patients on sildenafil, } 74 \% \text { of the patients on vardenafil } \\
\text { and } 72 \% \text { of the patients on tadalafil }\end{array}$ \\
\hline Lombardi et al. (40) & 65 & $10-20 \mathrm{mg}$ of tadalafil & $\begin{array}{l}\text { Patient using tadalafil maintained significant statistical improvement in erectile function, sexual satisfaction, and overall satisfaction } \\
\text { compared with baseline }(p<0.05)\end{array}$ \\
\hline Sánchez Ramos et al. ( & (41) 170 & Sildenafil $50 \mathrm{mg}$ & $\begin{array}{l}\text { It was reported by } 88.2 \% \text { of the patients and } 85.3 \% \text { of their partners that treatment with sildenafil had improved their erections, } \\
\text { regardless of the baseline characteristics of the spinal cord injury and erectile function }\end{array}$ \\
\hline
\end{tabular}


injury (41). Rizio et al. reviewed 10 articles, which used the IIEF to study satisfaction and/or efficacy of PDE5is sildenafil, tadalafil, and vardenafil in the treatment of ED. Minimal adverse effects were reported in the articles. Of the 739 patients studied in the 10 articles, only 102 patients reported any adverse effects, most of which were mild. Headache, flushing, hypotension, nasal congestion, and dyspepsia were the most commonly noted adverse reactions. These side effects are not only found in men with SCI but also in men without SCI who have ED (42). Patients with SCI, especially those with lesions above T6, are at great risk for hypotension. Sildenafil, can exacerbate this hypotension. Sildenafil induces significant hypotension in people with cervical level injuries more so than in thoracic level injuries and can cause dizziness in both populations (43). In another study, tadalafil use in people with SCI above T6 is safe with concerning not causing hypotension; hemodynamic changes that occurred $12-36 \mathrm{~h}$ post-administration were compensated for by elevations in heart rate (44).

ICI of vasoactive agents and intraurethral injection has been successfully used in the treatment of ED in patients with SCI. Trial results were summarized in Table 2 (4556). A pharmacologic erection program was given to the patient with SCI, using a fixed combination of prostaglandin El (PGE1) and papaverine. The dosage range was 0.10 to $0.50 \mathrm{cc}$. This simplified pharmacologic erection program offers safe, well-accepted, and effective therapy for ED to SCI population with very high patient satisfaction (45). Intracavernosal papaverine injection treatment was used to treat ED in SCI patients. Satisfactory erection sufficient for coital penetration was possible in $97 \%$ of patients (46). The ICI and self-injection of papaverine-phentolamine technique offer the possibility of achieving a full erection which continues for a few hours and disappears afterward in a group of SCI patients with erectile impotence (47).

Intraurethral prostaglandin E1 (alprostadil, MUSE)

Table 2.

Clinical trials testing the efficacy of PDE5i to treat ED in patients with $\mathrm{SCl}$.

\begin{tabular}{|lccc|}
\hline Authors & Agents used & $\begin{array}{c}\text { Mode of } \\
\text { administration }\end{array}$ & $\begin{array}{c}\text { Effective } \\
\text { or not for ED }\end{array}$ \\
\hline Zaslau et al. (45) & $\begin{array}{c}\text { Combination of PGE1 } \\
\text { and papaverine }\end{array}$ & ICl & Effective \\
\hline Kapoor et al. (46) & Papaverine injection & ICl & Effective \\
\hline Wyndaele et al. (47) & Papaverine-phentolamine & ICl & Effective \\
\hline Bodner et al. (48) & PGE1 (alprostadil, MUSE) & IUA & Effective \\
\hline Lebib Ben Achour et al. (49) & Alprostadil, moxisylite, papaverine & ICl & Effective \\
\hline Tang et al. (50) & PGE1 & ICl & Effective \\
\hline Hirsch et al. (51) & PGE1 & ICl & Effective \\
\hline $\begin{array}{l}\text { Earle et al. (52) } \\
\text { Sidi et al. (53) }\end{array}$ & $\begin{array}{c}\text { Papaverine, papaverine } \\
\text { plus phentolamine or PGE1 }\end{array}$ & ICl & Effective \\
\hline $\begin{array}{l}\text { Papaverine hydrochloride } \\
\text { or papaverine and } \\
\text { phentolamine mesylate }\end{array}$ & ICl & Effective \\
\hline Beretta et al. (54) & Papaverine & ICl & Effective \\
\hline Sønksen et al. (55) & Papaverine & ICl & Effective \\
\hline Momose et al. (56) & Papaverine hydrochloride & ICl & Effective \\
\hline $\begin{array}{l}\text { PGE1: prostaglandin E1, ICl: intracavernosal injection, SCl: spinal cord injury, ED: erectile dysfunction, } \\
\text { IUA: intraurethral administration. }\end{array}$ & & \\
\hline
\end{tabular}

appears to be somewhat effective in creating erections; however, these were less rigid erections than those obtained with ICI and provided less overall satisfaction. It should always be used in the patient with SCI after the placement of a constriction ring to prevent hypotension (48). A prospective study concerns 36 spinal cord injured men was implemented to confirm the efficiency of ICI in the treatment of ED in SCI patients and to determine the mean necessary dose to obtain a functional erection. The findings confirm the efficiency of ICI in the management of ED in SCI. The average doses required to obtain a functional erection was $12.3(+/-4.8)$ microgram with alprostadil and 14 (+/- 5.4) mg with moxisylyte (49). In another study, ICI of prostaglandin El had significantly improved the erectile condition of the patient with SCI. Patients received testing dosage starting from 5 micrograms with increasing dosage (maximum 20 micrograms) No systemic side effect or any other complication was noted except that pain at the injection site was complained of in two patients with an incomplete lesion (50). Vacuum erection devices (VED) can be presented to SCI men along with other options for treatment of ED. A study done by Denil et al. showed that after 3 months of the use of a VED, $93 \%$ of the men and $83 \%$ of the women reported rigidity sufficient for vaginal penetration, with an average duration of 18 minutes. VED is effective in many couples in the treatment of ED in SCI patients (57). A data from another trial suggest that VED is a feasible, safe, noninvasive alternative and possibly a better initial treatment for the management of impotence secondary to SCI (58). VED use is not without a risk, two cases of subcutaneous penile hemorrhage in patients using anticoagulant therapy and one case of penile gangrene occurred in three different SCI males (59).

Penile prostheses, introduced as the first effective organic treatment for ED over three decades ago, have an important role in the treatment of ED when other nonprosthetic treatment options have proven unsatisfactory (60).

The insertion of malleable penile prostheses in patients with SCI is associated with low complication rates and good patient satisfaction. Multiple studies showed its efficacy for ED in SCI patients, results are summarized in table 3 (61-65). A trial implemented by Kim et al., where a total of 48 patients with a SCI, who underwent malleable penile prosthesis (AMS 600) insertion from 1990 to 2004 were evaluated. The overall patient satisfaction rate was $79.2 \%$. Complications occurred in eight patients. Wound infections in four patients. Two patients were treated with conservative management, and two were managed through prostheses removal. Other complications were erosion in two patients, uncontrolled

\section{Table 3.}

Clinical trials testing the efficacy of penile prosthesis in patients with $\mathrm{SCl}$.

\begin{tabular}{|lcc|}
\hline \multicolumn{1}{|l}{ Authors } & \multicolumn{1}{c}{ Type of prosthesis } & Effective or not for ED \\
\hline Kim et al. (61) & Malleable & Effective \\
\hline Iwatsubo et al. (62) & Shirai-type silicone penile implants & Partially effective \\
\hline Green et al. (63) & Semi-rigid and inflatable prostheses & Effective \\
\hline Gross et al. (64) & Semi-rigid, semi-flexible or flexible prostheses & Effective \\
\hline SCl: spinal cord injury, ED: erectile dysfunction. & \\
\hline
\end{tabular}


penile pain owing to excessive prosthesis length in one patient, and supersonic transporter deformity in one patient (61). Iwatsubo et al. reported that the prosthesis improved sexual function in 15 (41\%) patients, 18 (48\%) patients were unchanged and four $(11 \%)$ patients were dissatisfied (62). Gross et al. reported that when paraplegic patients are able to regain sexual activity after successful implantation of a penile prosthesis, their self-confidence is increased (64).

In men with $\mathrm{SCI}$, sildenafil is the most effective treatment and is widely accepted. ICI, VED therapy in SCI patients should be used according to the patient's preference and choice (65). In SCI patients, penile implants may help to keep an external condom catheter in place and provide more penile stability for intermittent catheterization. However, they have an increased risk of infection. Semirigid rods have an increased risk of erosion. Although convenient to use, PDE5i are usually not effective in lower motor injuries. The hypotensive effects of intraurethral prostaglandins and PDE inhibitors need to be considered in SCI men with injuries at or above T6. ICI is very effective modality of therapy (66).

The Brindley procedure consists of a stimulator for sacral anterior-root stimulation and a rhizotomy of the dorsal sacral roots to abolish neurogenic detrusor overactivity. The Brindley procedure is suitable for a selected group of skeletally mature patients with complete SCI and detrusor overactivity. Erections can be evoked in a substantial number of patients, but results vary considerably. This can be explained by the relatively low number of patients that actually use the stimulator to evoke erections for sexual intercourse (0-32\%) (67). Lombardi et al. showed that $45 \%$ of men with incomplete SCI who were submitted to sacral neuromodulation reached and maintained a normal IIEF-5 score for $>3$ years (68).

\section{Erectile dysfunction (ED) in patients with Cerebrovascular accident}

A marked decline in sexual activity has been reported in stroke patients. SD and dissatisfaction with sexual life seem to be common both in male and female stroke patients and in their spouses. Decreased libido, sexual arousal, and satisfaction are related particularly to the presence of the hemisensory syndrome. The etiology for SD after stroke is multifactorial including both organic and psychosocial factors (69). A study found that the occurrence of ED after ischemic stroke was $77.8 \%$, significantly higher than the common ED. Stroke and ED have common risk factors, including hypertension and hyperlipidemia (70).

Acute ischaemic stroke in brain areas contributing to male sexual function may impair erectile function depending on the lesion site. There are an associations between stroke-related ED and lesion sites in the right occipito-parietal cortex and thalamus, as well as in the left insula and adjacent temporo-parietal areas. It was demonstrated associations between the deterioration of erectile function and lesion sites in the right occipital and thalamic region, and the left parietal association area (71). Jung et al. concluded in their study that the sexual desire, erectile function, and ejaculatory function were impaired after stroke. A lack of sexual desire was the major cause of an absence of sexual intercourse (72). If the right hemisphere is dominant for activation and this capacity is critical for normal sexual function, a greater incidence of impaired sexual function is occurred after right than after left hemisphere stroke $(73,74)$.

The presence of post stroke emotional incontinence (excessive/inappropriate laughing/crying) is a factor related to decreased post stroke sexual activity, more so in chronic than in subacute stages (75). Sexual disorders after stroke are thought to be due to multiple etiologies, including both organic (lesion localization, premorbid medical conditions, and medications) and psychosocial (fear of recurrences, loss of self-esteem, role changes, anxiety, and depression) (76).

As the sexual function is an important component to quality of life and activities of daily living, physicians and rehabilitation specialists, including physical, occupational, and speech therapists, should receive training in addressing sexuality in the treatment of post-stroke patients (77). Sexual rehabilitation needs to be an integrative part of stroke patients' rehabilitation process, preferably at the interdisciplinary level (78). Exploring individual stroke survivor counseling preferences periodically for recovery may be a useful strategy for delivering the desired information at the most appropriate time (79).

There is a lack of studies that assessed a pharmacological intervention for ED post-stroke. A RCT was implemented to assess the effectiveness of a structured sexual rehabilitation program compared with written information alone regarding sexual and psychological functioning. It concludes that the provision of written information alone appears to be as effective as a 30-min individualized sexual rehabilitation program in an inpatient setting (80). A study was done by Tibaek et al. to evaluate the effect of pelvic floor muscle training (PFMT) on measured erectile function as an indicator of sexuality in men with lower urinary tract symptoms after stroke. The data was insufficient to provide any reliable indication of benefit or risk of physical therapy targeted towards pelvic floor muscles for improving erectile function following stroke (81). Besides pharmacological treatment, one of the most important, but underestimated, success factors of ED therapy are undeniably a proper counseling, which is mandatory to provide correct information on post-stroke sexuality (82)

A systemic review had demonstrated that both neuroprotective and neurorestorative effects of PDE5i in animal models of stroke, though the specific underlying signaling pathways relating to PDE5 inhibition and cGMP may remain serendipitous in some studies. There is currently limited evidence on the effects of selective PDE5i in human stroke patients (83).

\section{Erectile dysfunction(ED) in patients with Parkinson's disease}

Parkinson's disease (PD) is the second most common progressive neurodegenerative disorder affecting older American adults and is predicted to increase in prevalence as the United States population ages. Resulting from a pathophysiologic loss or degeneration of dopaminergic neurons in the substantia nigra of the midbrain and the development of neuronal Lewy Bodies. Characterized by 
both motor and non-motor symptoms, PD patients classically display rest tremor, rigidity, bradykinesia, and stooping posture (84). Sexual dysfunction is one of the more disabling and poorly investigated aspects of PD. Several variables should be considered when evaluating SD in a disease in which physical, psychological, neurobiological, and pharmacological features merge and are not easily distinguishable (85). Dopamine has a fundamental role in the mediation of erectile function, whereas testosterone deficiency has been shown to be more common among PD patients than age-matched controls. Central regulation of erectile function is dependent on dopaminergic stimulation (86). In addition, hypothalamic dysfunction is mostly responsible for SD (decrease in libido and erection) in $\mathrm{PD}$, via altered dopamine-oxytocin pathways, which normally promote libido and erection (87).

The risk of PD was higher for patients with ED along with DM or hypertension than for patients without ED or counterpart comorbidities. ED has been reported as a risk factor for the development of PD (88).

Hypersexuality (HS) is usually considered to constitute a marked increase in sexual interest, arousal, and behavior, which has adverse consequences for the patient and their partner. HS, as a complication of treated PD, is rare in absolute terms, with estimates of prevalence from postal questionnaires and clinical surveys of approximately $2 \%$ to $4 \%$ ( 89 ).

Sildenafil citrate may be considered to treat ED in patients with PD as concluded in multiple studies, results are summarized in table 4 (90-94). A study was implemented by Raffaele et al. to assess the efficacy and safety of oral sildenafil, in depressed men with idiopathic PD and ED. Thirty-three men were enrolled in a 4month prospective, open-label, fixed-dose study, and received $50 \mathrm{mg}$ of sildenafil in the home setting approximately 1 hour before sexual activity, not more than once daily. At the end of the study, improved erections were reported by $84.8 \%$ of patients. Sildenafil significantly increased patients' ability to achieve and maintain erections. A clear improvement of depressive symptoms was observed in $75 \%$ of patients. Sildenafil was well tolerated in all the patients (91). In another study, there was statistically significant improvement in total Sexual Health Inventory for Men scores ( $23.8+/-2.0$ vs $16.6+/$ $2.8 ; p=0.01)$, overall sexual satisfaction $(p=0.03)$, satisfaction with sexual desire $(p=0.04)$ with use of sildenafil citrate for patients with PD (92). Sildenafil has no treatment effects for quality of life ( $\mathrm{p}=0.3)$ or PD symptoms (p = 0.86) (93).

Hussain et al. assess the efficacy and safety of sildenafil

\section{Table 4.}

Clinical trials testing the efficacy of Sildenafil for ED in patients with $P D$.

\begin{tabular}{|lccc|}
\hline Authors & N. of patients & Dosage of sildenadil & Effective or not for ED \\
\hline Raffaele et al (91) & 33 & $50 \mathrm{mg}$ & Effective \\
\hline Zesiewicz et al (92) & 10 & $50-100 \mathrm{mg}$ & Effective \\
\hline Bernard et al (93) & 20 & $\begin{array}{r}\text { Started at } 50 \mathrm{mg} \text { and adjusted } \\
\text { to } 25,50, \text { or } 100 \mathrm{mg} \text { after } 2 \text { weeks }\end{array}$ & Effective \\
\hline Hussain et al (94) & 12 & $50 \mathrm{mg}$ & Effective \\
\hline ED: erectile dysfunction, PD: Parkinson's Disease. & & \\
\hline
\end{tabular}

citrate in men with ED and Parkinsonism due either to PD or multiple system atrophy (MSA). Sildenafil citrate (50 $\mathrm{mg}$ ) is efficacious in the treatment of ED in both conditions; however, it may unmask or exacerbate hypotension in MSA. As PD may be diagnostically difficult to distinguish from MSA, especially in the early stages, measurement of lying and standing blood pressure before prescribing sildenafil to men with Parkinsonism was recommended (94). There were no clinical trials have studied the potential effectiveness of the other PDE-5 i (vardenafil or tadalafil) in the treatment of ED for the patient with PD.

Apomorphine, a short-acting D1- and D2-like receptor agonist, is the only drug proven to have efficacy equal to that of levodopa, albeit with a shorter time to onset and effect duration. Dopaminergic side effects such as nausea, somnolence, and hypotonia, are often mild (95). The benefit of apomorphine on sexual function in some patients suggests a possible role in the treatment of impotence in PD (96). A study was done by Heaton et al. evaluating the efficacy and side effects of apomorphine in men with no documentable organic cause of ED. Men with primarily psychogenic impotence were tested with one of four protocols of an apomorphine preparation (preliminary sublingual liquid, preliminary $5 \mathrm{mg}$ tablet, aqueous nasal spray, and new 3 and 4 mg controlled absorption tablets). Seven of 10 evaluable patients responded to the sublingual liquid preparation but the majority experienced significant nausea. The preliminary $5 \mathrm{mg}$ tablet and aqueous forms did not produce useful responses. The newly formulated controlled absorption 3 and $4 \mathrm{mg}$ tablets were tested in $12 \mathrm{men}$. Eight of 12 (67\%) developed erections (97). Its role in the management of ED has been suggested for men with PD but not totally validated.

Testosterone deficiency is associated with a decline in erectile function and testosterone levels are inversely correlated with increasing severity of ED. A significant proportion of men who fail to respond to a PDE5i are testosterone deficient (98). Testosterone deficiency may cause signs and symptoms of the nonmotor symptoms seen in $\mathrm{PD}$. In a prospective open-labeled pilot study, testosterone topical gel was administered daily to testosteronedeficient men with PD. A daily dose of transdermal testosterone gel improved testosterone deficiency symptoms in men with PD. Although there were trends in improvement in other nonmotor and motor symptoms of PD (99). In contrast, the results of the TEST-PD Study demonstrated that testosterone therapy was generally well-tolerated in elderly men with PD and probable testosterone deficiency. While there was no significant difference in the motor and nonmotor scales between the testosterone therapy and placebo groups at the end of 8 weeks compared with baseline (100). Urologist should be particularly cautious in the treatment of low testosterone concentrations in men with PD until more definitive studies were done.

Pergolide substantially improved sexual function in the younger male patients who were still interested in sexual activities. In such cases, the introduction of pergolide might be a better choice than treatment with sildenafil, which usually meets several contraindications in the com- 
mon PD male population (101). Dose reduction or discontinuation of a dopamine agonist is recommended when patients experience hypersexuality. Despite the lack of therapeutic options, discussing sexuality with PD patients remains essential. The hesitation of both patients and neurologists to discuss sexuality is what may cause an ongoing circle of avoidance. Routine screening for ED may break this vicious circle (102).

\section{Erectile dysfunction (ED) in patients with multiple sclerosis}

Multiple sclerosis (MS) is a chronic demyelinating disease of the central nervous system. The main autonomic nervous system disorders include sweating abnormalities, lower urinary tract dysfunctions, gastrointestinal symptoms and, SD. Among these, SD is common, but often underestimated symptom (103). The most common complaints of sexual dysfunction in men with MS are $\mathrm{ED}(50 \%-75 \%)$. One well-accepted hypothesis is that SD arises from spinal cord damage due to autoimmune responses. Recently, however, experts have suggested that SD in MS may be due not only to lesions affecting the neural pathways involved in physiologic function but also to psychological factors (104). ED in men with MS is related to neurological dysfunction, psychological factors, side effects of medication, or generalized MS symptoms, such as fatigue or micturition problems, usually in combination. The question of sexual dysfunction should always be broached during routine follow-up, regardless of age and social status (105).

Sildenafil treatment for ED in men with MS was effective and well-tolerated. A study implemented by Fowler et al. to assess the efficacy and safety of sildenafil citrate in men with MS and ED. Overall, 217 men received sildenafil $(25-100 \mathrm{mg} ; \mathrm{n}=104)$ or placebo $(\mathrm{n}=113)$ for 12 weeks. After 12 weeks, patients receiving sildenafil had higher mean scores for IIEF achieving and maintaining an erection compared with those receiving placebo ( $\mathrm{p}<$ $0.0001)$, and $89 \%(92 / 103)$ reported improved erections compared with $24 \%$ of patients receiving placebo ( $\mathrm{p}<$ $0.0001)$ (106). Another trial was enrolling 203 patients with MS, 102 into the sidenafil group, and 101 in the placebo group. Improved erections were reported by $32.8 \%$ of patients receiving sildenafil and $17.6 \%$ of those receiving placebo. Compared with placebo, sildenafil has little effect on MS emergent ED (107). Sildenafil cannot be recommended for the routine treatment of ED in every patient with MS. Tadalafil was proved as an effective and safe treatment for males with MS suffering from ED (108).

Intracavernous self-injection of vasoactive drugs is a wellaccepted therapy for the management of ED in neurogenic disorders. Vidal et al. presented the results of a selfinjection program in seven MS patients. All patients showed an excellent erectile response and had penile rigidity sufficient for sexual intercourse during an acceptable time, with minimal complications (109). ICI of papaverine was tested in a group of 29 patients with MS and ED. Acceptable rigidity was obtained in 27 patients of whom 23 started to use self-injections as treatment. Minor hematomas or ecchymoses were reported in 16 cases. Two patients developed penile indurations after 6 and 19 injections respectively (110). A study confirms the safety and efficacy of self-administered intracavernous PGE-1 for neuropathic impotence including the MS patients (111).

Counseling intervention is crucial for patients with MS and ED. Those interventions consist of counseling sessions, communication with the MS medical treatment team, education, and tailoring symptomatic treatments so they interfere less with sexual function (112).

\section{Erectile dysfunction (ED) in patients with epilepsy}

$\mathrm{SD}$ is a common comorbidity in people with epilepsy that adversely affects their quality of life. Nearly one-half of men and women with epilepsy have SD. There is limited evidence to indicate that sexual function improves in patients rendered seizure-free following epilepsy surgery. Multiple mechanisms including direct effects of epilepsy, effects of antiepileptic drugs (AED), and psychosocial factors contribute to SD in epilepsy. Circumstantial evidence indicates that seizures and interictal epileptiform discharges can directly affect the hypothalamic-pituitary axis as well as the production of gonadal steroids. Enzyme-inducing antiseizure drugs cause SD by affecting the metabolism of gonadal steroids (113). Clinicians need to investigate such problems carefully, both because of their multifactorial nature and because patients and physicians alike may often fail to recognize or be reluctant to acknowledge them (114). Epileptic men have been found to have an increased risk of ED of up to $57 \%$. Certain SD have been associated with specific periods of seizure activity, and fall into two discrete categories: those directly related to the epileptic discharge period (ictal), and those unrelated in time to seizure occurrence (interictal). Hypersexuality has been connected to ictal seizure activity while hyposexuality has been linked to interictal seizure activity (115).

Various studies have described an unusually common incidence of sexual and reproductive dysfunction in patients affected by temporal lobe epilepsy (TLE).

The results of a study done by Daniele et al. suggests a reduction of sexual interest in patients with right TLE as compared with left TLE in both men and women. No significant difference was found between right and left TLE groups concerning most aspects of sexual performance (116). Evidence suggests that people with temporal lobe epilepsy have reduced genital blood flow in response to erotic stimulation; the etiology of this phenomenon is not well understood, but disruption of the limbic and frontal cortex by epileptic activity may be implicated (117). Epileptic discharges from the temporal lobe may influence the release of hormones from the hypothalamic-pituitary axis. Serum androgen concentrations in men with epilepsy are significantly low in men with seizures $(118,119)$.

It is noticeable that AEDs may also alter endocrine function in both men and women with epilepsy and this alteration may lead to clinically significant reproductive endocrine disorders in certain cases. In recent years, the effects of enzyme-inducing AEDs on androgen metabolism have been evoked as a possible etiologic factor. These drugs have been found to cause an increase in total testosterone and sex hormone-binding globulin 
(SHBG), but a decrease in free testosterone (120). The enzyme stimulating AEDs (phenytoin, topiramate, phenobarbital, and carbamazepine) raise the hepatic synthesis of SHBG that lessens the accessibility of testosterone. Additionally, enhanced sex hormone metabolism and contraceptive hormones are not found with the use of AEDs that do not stimulate hepatic enzymes (lamotrigine, valproate, gabapentin, and vigabatrin) (121). Management of SD thought to be caused by anti-convulsants should include the cessation of the offending drug, and consideration of switching to alternative anti-convulsants that have been reported to improve sexual function such as oxcarbazepine, and lamotrigine (122). A study showed that switching AED treatment from carbamazepine to oxcarbazepine in men with epilepsy can reduce the ED side effects observed with carbamazepine (123).

Adding testosterone for a short time in cases of low-normal testosterone levels (300 to $400 \mathrm{ng} / \mathrm{dL}$ ) seems helpful in some men who did not respond to initial treatment with PDE-5i alone and in whom testosterone therapy is not contraindicated (124). Concentrating on hormone levels alone as an explanation of SD in epilepsy represents an overly simplistic approach to the problem (125). The therapy of SD in epilepsy depends on its cause. In cases of hormonal alterations, the first step is a change of antiepileptic regimen. Instead of enzymeinductor antiepileptics and valproate, new antiepileptic drugs should be prescribed. At present, the most investigated antiepileptic drug is the oxcarbazepine with a positive effect on antiepileptic-induced male SD, however, lamotrigine seems to be also beneficial. If the hormonal and SD cannot be eliminated by drug changes, androgenic therapy or bromocriptine may be required. Testosterone may not only be beneficial on sexual functions but can reduce also the seizure frequency (126).

Evidence suggests an influence of PDE5i on seizure susceptibility in humans. In addition, preclinical studies have demonstrated the role of nitric oxide metabolites in the facilitation of the paroxysmal phenomenon (127). Recent evidence indicates that sildenafil may exert some central effects through the enhancement of nitric oxide (NO)-mediated effects. NO is known to have modulatory effects on seizure threshold, raising the possibility that sildenafil may alter seizure susceptibility through NOmediated mechanisms (128). Although generalized tonic-clonic seizures were reported in a healthy man after taking tadalafil, the influence of tadalafil on seizure susceptibility has not been studied so far. A study was to investigate the effect of tadalafil on seizure threshold in three acute seizure tests in mice. It concludes that tadalafil may increase the risk of myoclonic seizure and decrease the anticonvulsant efficacy of oxcarbazepine (129). In summary, PDE5i should be used with great caution in men with epilepsy.

\section{Erectile dysfunction (ED) in patients with Herniated disc}

Lumbar disc herniation (LDH) is the most common pathologic condition that is responsible for radicular pain. In patients non-responsive to medical therapy disc surgery is indicated. Lumbosacral disc disease may interfere with the nerve transmission for erection through multiple autonomic and somatic pathways (129). Braun et al. reported that herniated disc was seen in $23.2 \%$ of 8000 men with ED (130). Akbas et al. implemented a study to evaluate patients' sexual problems and sexual behavior patterns before and after surgical treatment of LDH. Forty-three patients were included in the study (mean age 41.4 years). The frequency of sexual intercourse before the operation was reduced by $78 \%$ of cases compared with the pain-free period. The frequency of intercourse was found to have increased ( $p=0.01$ ), while the description of any type of sexual problem had decreased $(\mathrm{p}=0.005)$ significantly (131). LDH largely impacted sexual desire, activity, and satisfaction. Adjustment in sexual position was required in a large number of patients to avoid discomfort during sexual activities. Surgical treatment improved the quality of sexual activities (132). In another study, ED was more frequent in patients with $\mathrm{LDH}$, the treatment of LDH had positive effects on ED (133).

Akca et al. reported four patients with sexual and sphincter dysfunction, including two women and two men, aged between 20 and 52 years. All patients had a perianal sensory deficit and sexual and sphincter dysfunction. Magnetic resonance imaging (MRI) of three patients displayed a large extruded disc fragment at the L5-S1 level. A syndrome with a perianal sensory deficit, paralysis of the sphincter, and SD may occur in patients with lumbar L5-S1 disc disease. The improvement of perianal sensory deficit after surgery was counteracted by a trend toward disturbed sexual function (134). Xu et al. studied 90 male patients with intervertebral disc herniation treated by a lumbar discectomy, who were divided into three age groups of equal number: groups $\mathrm{A}(<45 \mathrm{yr}), \mathrm{B}(45-$ $55 \mathrm{yr}$ ) and $\mathrm{C}$ ( $>55 \mathrm{yr})$. They obtained the IIEF- 5 scores of the patients preoperatively and at 12 months after surgery. The IIEF- 5 scores at 12 months after surgery were $21.3+/-3.3,16.8+/-1.3$ and $14.1+/-1.0$ in groups A, $\mathrm{B}$ and $\mathrm{C}$. Group A showed better improved erectile function than B and C $([51.17+/-6.25] \%$ vs $[36.31+/-$ $4.28] \%$ and $[22.71+/-5.68] \%, \mathrm{p}<0.05)$. Early decompression surgery according to different etiological factors is very important for erectile function recovery in young and middle-aged male patients (135).

One of the consequences of the discopathy is pressure on the spinal cord or nerve roots that supply the genitals and sexual centers located in the cord. In addition, the accompanying pain and limitation of mobility can lead to the occurrence of SD. The pain and neurological symptoms associated with intervertebral disc disease reduce the patients' satisfaction with their sex lives. Patients with lumbosacral discopathy noted a change in sexual performance, often resulting in passivity, discouragement, weakness, or a complete lack of interest in sex. The disorders also affect the emotional state (136). There is significant sexual impairment in men with lesions of the cauda equina or conus medullaris. This is poorly correlated with neurological and EMG findings and has received insufficient medical attention (137).

Choy et al. describe the case of two patients with ED who were treated with percutaneous laser disc decompression as outpatients. In addition to the early return of erectile function in both cases, immediate pain relief was 
achieved in the second case. Follow-up visits confirmed continued normal sexual function and lack of pain (138). Orlin et al. reported a case of a 35-year-old male with normal erectile function up until the age of 18 years subsequently suffered permanent ED for the next 17 years. CT of the lumbar spine showed a large protrusion of the intervertebral disc L5-S1. After operative removal of the protrusion, a normal erection was achieved after 15 days and urine flow improved at 1 and 2 months and became normal after 3 months. Both erectile and bladder functions continued to be normal 10 years later. Thus, the effects of long-lasting mechanical compression of parasympathetic nerves need not be irreversible (139). Kulaksizoglu et al. assessed the effect of lumbar disc herniation surgery for low back pain on the erectile functioning. They reported that ED rates have improved in $31.7 \%$ of those previously with ED in a 3 month period after the surgery. Best results were obtained in those patients with mild ED preoperatively. Moderate and severe ED may be related to a more severe nerve injury or to vascular and/or psychiatric factors. Evaluation of erectile functioning should routinely be performed in patients with lumbosacral disc disease (140).

\section{Erectile dysfunction (ED) in patients with multiple system atrophy}

Multiple system atrophy (MSA) is a sporadic and rapidly progressive neurodegenerative disorder that presents with autonomic failure in combination with Parkinsonism or cerebellar ataxia. Novel therapeutic options targeting disease modification have been investigated in clinical trials. These include riluzole, recombinant human growth hormone, and minocycline (141). Urinary and ED symptoms are prominent early features in men with MSA. Autonomic failure, considered until recently to be the cause of ED in these men, is commonly expressed through symptoms of orthostatic hypotension. In a study conducted by Kirchhof et al., the onset of ED had preceded the onset of bladder symptoms in 58\% and the onset of hypotension symptoms in $91 \%$ of these men. The earlier occurrence of ED in men with MSA suggests a lack of a causal relationship to hypotension (142).

There is an ongoing debate on the causes of ED in MSA. Impairment of dopaminergic mediated pathways in the central nervous system, which is heavily implicated in erectile function, is most likely involved. Other diseaserelated factors such as psychosocial stress, the burden of chronic illness, changed appearance, fatigue, and relative immobility contribute to ED (143).

Sildenafil citrate ( $50 \mathrm{mg}$ ) is efficacious in the treatment of ED in parkinsonism due to PD or MSA; however, it may unmask or exacerbate hypotension in MSA (94). Its administration may not be recommended in patients with symptomatic orthostatic hypotension. The use of direct injections of alprostadil, either intracavernosal or intraurethral is another option (144).

\section{Erectile dysfunction (ED) in patients with peripheral neuropathy}

Peripheral nervous system (PNS) disorders may cause SD in patients of both genders. These disorders include mainly polyneuropathies (particularly those affecting the autonomic nervous system and localized lesions affecting the innervation of genital organs. Impaired neural control may produce a malfunction of the genital response consisting of loss of genital sensitivity, ED, ejaculation disorder, and orgasmic disorder (145). Diabetic neuropathy was diagnosed if the patients showed two or more of the following three characteristics: neuropathic symptoms decreased or disappeared Achilles tendon reflex and/or abnormal vibration perception. A study that included 287 male Japanese patients with DM type 2 , age (19-65 years) was implemented to demonstrate that diabetic neuropathy is positively associated with severe erectile dysfunction among Japanese DM type 2 patients aged $<65$ years (146).

The proposed mechanisms of ED in diabetic patients are represented by vasculopathy, neuropathy, visceral adiposity, insulin resistance, and hypogonadism. Both somatic and autonomic neuropathies may contribute to diabetes-induced ED due to the impairment of sensory impulses from the penis to the reflexogenic erectile center (147). In an attempt to understand better the role of vascular and neurogenic alterations in the pathophysiology of diabetic impotence, Benvenuti et al. studied 29 impotent male patients with DM. Results confirm that vascular obstruction, more than nerve damage, plays a primary role in the pathophysiology of diabetic erectile failure, and stress the importance of psychogenic factors. The observation that some patients presented marked involvements of both arterial supply and neurological pathways only a few years, or even 1 year, after the diagnosis of the disease, indicates the need for an early screening of the vascular and neurological status, even in asymptomatic patients (148). While Hecht et al. found that the tests indicating neuropathy showed abnormalities in men with diabetic ED as frequently as in men with neuropathic ED. Some tests even suggested neuropathy more often in diabetic than in neuropathic ED (149). The microvascular deficit in the vasa nervorum of nerve trunks and ganglia is a major trigger for a cascade of events that eventually lead to diabetic neuropathy and autonomic neuropathy. ED is a consequence of these events and if not treated early may become irreversible. Diabetes-induced ED are often resistant to PDE5i treatment (150).

First-, second- and third-line therapy may be applied. PDE5i treatment from the first-line options leads to smooth muscle relaxation in the corpus cavernosum and enhancement in blood flow, resulting in erection during the sexual stimulation. The use of PDE-5i in the presence of oral nitrates is strictly contraindicated in diabetic men. All PDE-5i have been evaluated for ED in diabetic patients with convincing efficacy data. Second-line therapy includes intracavernosal, trans- or intraurethral administration of vasoactive drugs or application of a vacuum device. Third-line therapies are the implantation of penile prosthesis and penile revascularization (151). Gene therapy strategies that can enhance NO production or NO-mediated signaling pathways, growth factormediated nerve regeneration, or $\mathrm{K}^{+}$channel activity in the smooth muscle could be promising approaches for the treatment of ED. For the neurogenic type of ED induced by diabetes or cavernous nerve injury, genes 
encoding different types of neurotrophic factors, which can enhance nerve regeneration, have been proposed for ED gene therapy. The recent clinical study using nonviral gene therapy of the $\mathrm{Ca}^{2+}$ activated $\mathrm{BK}(\mathrm{Max}-\mathrm{K})$ channel for ED patients shows great promise for future development of gene-based therapy of ED (152).

The adoption of anatomic radical prostatectomy (RP) with cavernous nerve preservation by many surgeons, the rate of postoperative recovery of erectile function sufficient for sexual intercourse has improved dramatically. Pharmacologic rehabilitation has rapidly emerged as a clinical strategy to reduce the incidence of ED after radical prostatectomy (153). Post prostatectomy ED appears to be initiated by neuropraxia and perpetuated by cavernosal smooth muscle apoptosis. Sildenafil has been studied in a novel primary prevention modality using nightly administration after a bilateral nerve-sparing prostatectomy. In this novel approach, it affected a sevenfold improvement in return of spontaneous, normal erectile function 2 months after drug discontinuation (154). Preclinical data and several prospective randomized trials have demonstrated the value of treating patients with oral PDE5i after surgery, with the concomitant potential benefit of early re-oxygenation of the erectile tissue. For patients who do not properly respond to PDE5is, proper counseling regarding intracavernous treatment should be considered, along with the further possibility of surgical treatment for ED involving the implantation of a penile prosthesis (155). A proper algorithm or a clinical guideline for the post RP-ED has not been established until now.

\section{Conclusions}

Sexual and function are important factors contributing to the quality of life in patients with neurologic disease. Neurogenic ED is a complex problem. Sexual functioning should be regularly evaluated during a long-term rehabilitation program, and any existing ED should be included in the treatment plan. New drugs and treatment options may help to improve the treatment and quality of life of patients with neurologic conditions.

\section{REFERENCES}

1. Fabbri A, Aversa A, Isidori A. Erectile dysfunction: an overview. Hum Reprod Update. 1997; 3:455-466.

2. Yafi FA, Jenkins L, Albersen M, et al. Erectile dysfunction. Nat Rev Dis Primers. 2016; 2:16003.

3. Pastuszak AW. Current diagnosis and management of erectile dysfunction. Curr Sex Health Rep. 2014; 6:164-176.

4. Persu C, Cauni V, Gutue S, et al. Diagnosis and treatment of erectile dysfunction--a practical update. J Med Life. 2009; 2:394-400.

5. Papagiannopoulos D, Khare N, Nehra A. Evaluation of young men with organic erectile dysfunction. Asian J Androl. 2015; 17:11-16.

6. Glina S, Cohen DJ, Vieira M. Diagnosis of erectile dysfunction. Curr Opin Psychiatry. 2014; 27:394-399.

7. Lasker GF, Maley JH, Kadowitz PJ. A review of the pathophysiology and novel treatments for erectile dysfunction. Adv Pharmacol Sci. 2010; 2010:730861.
8. Heidelbaugh JJ. Management of erectile dysfunction. Am Fam Physician. 2010; 81:305-312.

9. Fazio L, Brock G. Erectile dysfunction: management update. CMAJ. 2004; 170:1429-1437.

10. Bertero EB, Antunes DL. Surgical treatment of erectile dysfunction. Sex Med Rev. 2015; 3:316-327.

11. Bettocchi C, Palumbo F, Spilotros M, et al. Penile prostheses. Ther Adv Urol. 2010; 2:35-40.

12. Calabrò RS, Gervasi G, Naro A, et al. Erectile dysfunction in individuals with neurologic disability: a hospital-based cross-sectional study. Innov Clin Neurosci. 2016; 13:10-14.

13. Dean RC, Lue TF. Physiology of penile erection and pathophysiology of erectile dysfunction. Urol Clin North Am. 2005; 32:379-v.

14. Giuliano F, Rampin O. Neural control of erection. Physiol Behav. 2004; 83:189-201.

15. Yang CC, Jiang X. Clinical autonomic neurophysiology and the male sexual response: an overview. J Sex Med. 2009; 6 (Suppl 3):221-228.

16. Giuliano F, Rampin O, Brown K, et al. Stimulation of the medial preoptic area of the hypothalamus in the rat elicits increases in intracavernous pressure. Neurosci Lett. 1996; 209:1-4.

17. McKenna KE. Central control of penile erection. Int J Impot Res. 1998; 10 (Suppl 1):S25-S34.

18. Andersson KE. Neurophysiology/pharmacology of erection. Int J Impot Res. 2001; 13 (Suppl 3):S8-S17.

19. Opsomer RJ, Boccasena P, Traversa R, Rossini PM. Sympathetic skin responses from the limbs and the genitalia: normative study and contribution to the evaluation of neurourological disorders. Electroencephalogr Clin Neurophysiol. 1996; 101:25-31.

20. Valles-Antuña C, Fernandez-Gomez J, Escaf S, et al. Sympathetic skin response in patients with erectile dysfunction. BJU Int. 2009; 104:1709-1712.

21. Yilmaz U, Soylu A, Ozcan C, et al. Evoked cavernous activity. J Urol. 2002; 167:188-191.

22. Yang CC, Yilmaz U, Vicars BG. Evoked cavernous activity: normal values. J Urol. 2008; 179:2312-2316.

23. Jiang XG, Speel TG, Wagner G, et al. COST Action B18 project. The value of corpus cavernosum electromyography in erectile dysfunction: current status and future prospect. Eur Urol. 2003; 43:211-218.

24. Chen Y, Tang Y, Vogel LC, Devivo MJ. Causes of spinal cord injury. Top Spinal Cord Inj Rehabil. 2013; 19:1-8.

25. Ramos AS, Samsó JV. Specific aspects of erectile dysfunction in spinal cord injury. Int J Impot Res. 2004; 16 (Suppl 2):S42-S45.

26. Hess MJ, Hough S. Impact of spinal cord injury on sexuality: broad-based clinical practice intervention and practical application. J Spinal Cord Med. 2012; 35:211-218.

27. Albright TH, Grabel Z, DePasse JM, et al. Sexual and Reproductive Function in Spinal Cord Injury and Spinal Surgery Patients. Orthop Rev 2015; 7:5842.

28. Ferro JKO, Lemos A, Silva CPD, et al. Predictive factors of male sexual dysfunction after traumatic spinal cord injury. Spine 2019; 44:1228-1237.

29. Aikman K, Oliffe JL, Kelly MT, McCuaig F. Sexual health in men with traumatic spinal cord injuries: a review and recommendations for primary health-care providers. Am J Mens Health. 2018; 12:2044-2054. 
30. Biering-Sørensen F, Sønksen J. Sexual function in spinal cord lesioned men. Spinal Cord. 2001; 39:455-470.

31. Khorrami MH, Javid A, Moshtaghi D, et al. Sildenafil efficacy in erectile dysfunction secondary to spinal cord injury depends on the level of cord injuries. Int J Androl. 2010; 33:861-864.

32. Derry F, Hultling C, Seftel AD, Sipski ML. Efficacy and safety of sildenafil citrate (Viagra) in men with erectile dysfunction and spinal cord injury: a review. Urology. 2002; 60 (Suppl 2):49-57.

33. Ohl DA, Carlsson M, Stecher VJ, Rippon GA. Efficacy and safety of sildenafil in men with sexual dysfunction and spinal cord injury. Sex Med Rev. 2017; 5:521-528.

34. Ergin S, Gunduz B, Ugurlu H, et al. A placebo-controlled, multicenter, randomized, double-blind, flexible-dose, two-way crossover study to evaluate the efficacy and safety of sildenafil in men with traumatic spinal cord injury and erectile dysfunction. J Spinal Cord Med. 2008; 31:522-531.

35. Giuliano F, Hultling C, El Masry WS, et al. Randomized trial of sildenafil for the treatment of erectile dysfunction in spinal cord injury. Sildenafil Study Group. Ann Neurol. 1999; 46:15-21.

36. Gans WH, Zaslau S, Wheeler S, et al. Efficacy and safety of oral sildenafil in men with erectile dysfunction and spinal cord injury. J Spinal Cord Med. 2001; 24:35-40.

37. Giuliano F, Sanchez-Ramos A, Löchner-Ernst D, et al. Efficacy and safety of tadalafil in men with erectile dysfunction following spinal cord injury. Arch Neurol. 2007; 64:1584-1592.

38. Del Popolo G, Li Marzi V, Mondaini N, Lombardi G. Time/duration effectiveness of sildenafil versus tadalafil in the treatment of erectile dysfunction in male spinal cord-injured patients. Spinal Cord. 2004; 42:643-648.

39. Soler JM, Previnaire JG, Denys P, Chartier-Kastler E. Phosphodiesterase inhibitors in the treatment of erectile dysfunction in spinal cord-injured men. Spinal Cord. 2007; 45:169-173.

40. Lombardi G, Macchiarella A, Cecconi F, Del Popolo G. Efficacy and safety of medium and long-term tadalafil use in spinal cord patients with erectile dysfunction. J Sex Med. 2009; 6:535-543.

41. Sánchez Ramos A, Vidal J, Jáuregui ML, et al. Efficacy, safety and predictive factors of therapeutic success with sildenafil for erectile dysfunction in patients with different spinal cord injuries. Spinal Cord. 2001; 39:637-643.

42. Rizio N, Tran C, Sorenson M. Efficacy and satisfaction rates of oral PDE5is in the treatment of erectile dysfunction secondary to spinal cord injury: a review of literature. J Spinal Cord Med. 2012; 35:219-228.

43. Ethans KD, Casey AR, Schryvers OI, MacNeil BJ. The effects of sildenafil on the cardiovascular response in men with spinal cord injury at or above the sixth thoracic level. J Spinal Cord Med. 2003; $26: 222-226$

44. Ethans KD, Casey A, Tarhoni M, et al. A randomized doubleblind, placebo-controlled, cross-over trial assessing the effect of tadalafil (Cialis) on the cardiovascular response in men with complete spinal cord injury above the sixth thoracic level: A pilot study. Spinal Cord Ser Cases. 2018; 4:105.

45. Zaslau S, Nicolis C, Galea G, et al. A simplified pharmacologic erection program for patients with spinal cord injury. J Spinal Cord Med. 1999; 22:303-307.

46. Kapoor VK, Chahal AS, Jyoti SP,, et al. Intracavernous papaverine for impotence in spinal cord injured patients. Paraplegia. 1993; 31:675-677.

47. Wyndaele JJ, de Meyer JM, de Sy WA, Claessens $H$.
Intracavernous injection of vasoactive drugs, an alternative for treating impotence in spinal cord injury patients. Paraplegia. 1986; 24:271-275.

48. Bodner DR, Haas CA, Krueger B, Seftel AD. Intraurethral alprostadil for treatment of erectile dysfunction in patients with spinal cord injury. Urology. 1999; 53:199-202.

49. Lebib Ben Achour S, Laffont I, et al. Utilisation des injections intracaverneuses dans les dysfonctionnements érectiles du blessé médullaire : à propos d'une expérience sur 36 patients [Intracavernous injections in the treatment of erectile dysfunction in spinal cord injured patients: experience with 36 patients]. Ann Readapt Med Phys. 2001; 44:35-40.

50. Tang SF, Chu NK, Wong MK. Intracavernous injection of prostaglandin E1 in spinal cord injured patients with erectile dysfunction. A preliminary report. Paraplegia. 1995; 33:731-733.

51. Hirsch IH, Smith RL, Chancellor MB, et al. Use of intracavernous injection of prostaglandin E1 for neuropathic erectile dysfunction. Paraplegia. 1994; 32:661-664.

52. Earle CM, Keogh EJ, Ker JK, et al. The role of intracavernosal vasoactive agents to overcome impotence due to spinal cord injury. Paraplegia. 1992; 30:273-276.

53. Sidi AA, Cameron JS, Dykstra DD, et al. Vasoactive intracavernous pharmacotherapy for the treatment of erectile impotence in men with spinal cord injury. J Urol. 1987; 138:539-542.

54.Beretta G, Zanollo A, Fanciullacci F, Catanzaro F. Intracavernous injection of papaverine in paraplegic males. Acta Eur Fertil. 1986; $17: 283-284$.

55. Sønksen JO, Hansen EF, Biering-Sørensen F, Colstrup H. Intrakavernøs selvinjektion til behandling af erektiv dysfunktion hos rygmarvsskadede [Intracavernous self-injection for treatment of erectile dysfunction inpatients with spinal cord injuries]. Ugeskr Laeger. 1990; 152:3006-3009.

56. Momose H, Natsume O, Yamamoto M, et al. Hinyokika Kiyo. 1987; 33:1065-1069.

57. Denil J, Ohl DA, Smythe C. Vacuum erection device in spinal cord injured men: patient and partner satisfaction. Arch Phys Med Rehabil. 1996; 77:750-753.

58. Seckin B, Atmaca I, Ozgok Y, et al. External vacuum device therapy for spinal cord injured males with erectile dysfunction. Int Urol Nephrol. 1996; 28:235-240.

59. Rivas DA, Chancellor MB. Complications associated with the use of vacuum constriction devices for erectile dysfunction in the spinal cord injured population. J Am Paraplegia Soc. 1994; 17:136139.

60. Mulcahy JJ, Austoni E, Barada JH, et al. The penile implant for erectile dysfunction. J Sex Med. 2004; 1:98-109.

61. Kim YD, Yang SO, Lee JK, et al. Usefulness of a malleable penile prosthesis in patients with a spinal cord injury. Int J Urol. 2008; 15:919-923

62. Iwatsubo E, Tanaka M, Takahashi K, Akatsu T. Non-inflatable penile prosthesis for the management of urinary incontinence and sexual disability of patients with spinal cord injury. Paraplegia. 1986; 24:307-310.

63. Green BG, Sloan SL. Penile prostheses in spinal cord injured patients: combined psychosexual counselling and surgical regimen. Paraplegia. 1986; 24:167-172.

64. Gross AJ, Sauerwein DH, Kutzenberger J, Ringert RH. Penile prostheses in paraplegic men. Br J Urol. 1996; 78:262-264.

65. Moemen MN, Fahmy I, AbdelAal M, et al. Erectile dysfunction 
in spinal cord-injured men: different treatment options. Int J Impot Res. 2008; 20:181-187.

66- Linsenmeyer TA. Treatment of erectile dysfunction following spinal cord injury. Curr Urol Rep. 2009; 10:478-484.

67. Martens FM, Heesakkers JP. Clinical results of a brindley procedure: sacral anterior root stimulation in combination with a rhizotomy of the dorsal roots. Adv Urol. 2011; 2011:709708.

68. Lombardi G, Musco S, Kessler TM, et al. Management of sexual dysfunction due to central nervous system disorders: a systematic review. BJU Int. 2015; 115 (Suppl 6):47-56.

69. Korpelainen JT, Kauhanen ML, Kemola H, et al. Sexual dysfunction in stroke patients. Acta Neurol Scand. 1998; 98:400-405.

70. Dai H, Wang J, Zhao Q, et al. Erectile dysfunction and associated risk factors in male patients with ischemic stroke: A cross-sectional study. Medicine (Baltimore). 2020; 99: e18583.

71. Winder K, Seifert F, Köhrmann M, et al. Lesion mapping of stroke-related erectile dysfunction. Brain. 2017; 140:1706-1717.

72. Jung JH, Kam SC, Choi SM, et al. Sexual dysfunction in male stroke patients: correlation between brain lesions and sexual function. Urology. 2008; 71:99-103.

73. Coslett HB, Heilman KM. Male sexual function. Impairment after right hemisphere stroke. Arch Neurol. 1986; 43:1036-1039.

74. Sikiru L, Shmaila H, Yusuf GS. Erectile dysfunction in older male stroke patients: correlation between side of hemiplegia and erectile function. Afr J Reprod Health. 2009; 13:49-54.

75. Choi-Kwon S, Kim JS. Poststroke emotional incontinence and decreased sexual activity. Cerebrovasc Dis. 2002; 13:31-37.

76. Calabrò RS, Gervasi G, Bramanti P. Male sexual disorders following stroke: an overview. Int J Neurosci. 2011; 121:598-604.

77. Rosenbaum T, Vadas D, Kalichman L. Sexual function in poststroke patients: considerations for rehabilitation. J Sex Med. 2014; 11:15-21.

78. Grenier-Genest A, Gérard M, Courtois F. Stroke and sexual functioning: A literature review. NeuroRehabilitation. 2017; 41:293-315.

79. Stein J, Hillinger M, Clancy C, Bishop L. Sexuality after stroke: patient counseling preferences. Disabil Rehabil. 2013; 35:18421847.

80. Ng L, Sansom J, Zhang N, et al. Effectiveness of a structured sexual rehabilitation programme following stroke: A randomized controlled trial. J Rehabil Med. 2017; 49:333-340.

81. Tibaek S, Gard G, Dehlendorff C, et al. The effect of pelvic floor muscle training on sexual function in men with lower urinary tract symptoms after stroke. Top Stroke Rehabil. 2015; 22:185-193.

82. Calabrò RS, Bramanti P. Post-stroke sexual dysfunction: an overlooked and under-addressed problem. Disabil Rehabil. 2014; 36:263-264.

83. Ölmestig JNE, Marlet IR, Hainsworth AH, Kruuse C. Phosphodiesterase 5 inhibition as a therapeutic target for ischemic stroke: A systematic review of preclinical studies. Cell Signal. 2017; 38:39-48.

84. Beitz JM. Parkinson's disease: a review. Front Biosci (Schol Ed). 2014; 6:65-74.

85. Meco G, Rubino A, Caravona N, Valente M. Sexual dysfunction in Parkinson's disease. Parkinsonism Relat Disord. 2008; 14:451-456.

86. Gao X, Chen H, Schwarzschild MA, et al. Erectile function and risk of Parkinson's disease. Am J Epidemiol. 2007; 166:1446-1450.
87. Sakakibara R, Kishi M, Ogawa E, et al. Bladder, bowel, and sexual dysfunction in Parkinson's disease. Parkinsons Dis. 2011; 2011:924605.

88. Yang Y, Liu H, Lin T, Kuo Y, Hsieh T. Relationship between erectile dysfunction, comorbidity, and Parkinson's disease: evidence from a population-based longitudinal study. J Clin Neurol. 2017; $13: 250-258$

89. Codling D, Shaw P, David AS. Hypersexuality in Parkinson's disease: systematic review and report of 7 new cases. Mov Disord Clin Pract. 2015; 2:116-126.

90. Zesiewicz TA, Sullivan KL, Arnulf I, et al. Practice parameter: treatment of nonmotor symptoms of Parkinson disease: report of the Quality Standards Subcommittee of the American Academy of Neurology. Neurology. 2010; 74:924-931.

91. Raffaele R, Vecchio I, Giammusso B, et al. Efficacy and safety of fixed-dose oral sildenafil in the treatment of sexual dysfunction in depressed patients with idiopathic Parkinson's disease. Eur Urol. 2002; 41:382-386.

92. Zesiewicz TA, Helal M, Hauser RA. Sildenafil citrate (Viagra) for the treatment of erectile dysfunction in men with Parkinson's disease. Mov Disord. 2000; 15:305-308.

93. Bernard BA, Metman LV, Levine L, et al. Sildenafil in the treatment of erectile dysfunction in Parkinson's disease. Mov Disord Clin Pract. 2016; 4:412-415.

94. Hussain IF, Brady CM, Swinn MJ, et al. Treatment of erectile dysfunction with sildenafil citrate (Viagra) in parkinsonism due to Parkinson's disease or multiple system atrophy with observations on orthostatic hypotension. J Neurol Neurosurg Psychiatry. 2001; 71:371-374.

95. Carbone F, Djamshidian A, Seppi K, Poewe W. Apomorphine for Parkinson's disease: efficacy and safety of current and new formulations. CNS Drugs. 2019; 33:905-918.

96. O'Sullivan JD, Hughes AJ. Apomorphine-induced penile erections in Parkinson's disease. Mov Disord. 1998; 13:536-539.

97. Heaton JP, Morales A, Adams MA, et al. Recovery of erectile function by the oral administration of apomorphine. Urology. 1995; 45:200-206.

98. Blute M, Hakimian P, Kashanian J, et al. Erectile dysfunction and testosterone deficiency. Front Horm Res. 2009; 37:108-122.

99. Okun MS, Walter BL, McDonald WM, et al. Beneficial effects of testosterone replacement for the nonmotor symptoms of Parkinson disease. Arch Neurol. 2002; 59:1750-1753.

100. Okun MS, Fernandez HH, Rodriguez RL, et al. Testosterone therapy in men with Parkinson disease: results of the TEST-PD Study. Arch Neurol. 2006; 63:729-735.

101. Pohanka M, Kanovský P, Bares M, et al. Pergolide mesylate can improve sexual dysfunction in patients with Parkinson's disease: the results of an open, prospective, 6-month follow-up. Eur J Neurol. 2004; 11:483-488.

102. van Hees PJ, van der Plas AA, van Ek GF, et al. Discussing sexuality with patients with Parkinson's disease: a survey among Dutch neurologists. J Neural Transm (Vienna). 2017; 124:361-368.

103. Balsamo R, Arcaniolo D, Stizzo M, et al. Increased risk of erectile dysfunction in men with multiple sclerosis: an Italian cross-sectional study. Cent European J Urol. 2017; 70:289-295.

104. Guo ZN, He SY, Zhang HL, et al. Multiple sclerosis and sexual dysfunction. Asian J Androl. 2012; 14:530-535.

105. Landtblom AM. Treatment of erectile dysfunction in multiple sclerosis. Expert Rev Neurother. 2006; 6:931-935. 
106. Fowler CJ, Miller JR, Sharief MK, et al. A double blind, randomised study of sildenafil citrate for erectile dysfunction in men with multiple sclerosis. J Neurol Neurosurg Psychiatry. 2005; 76:700-705.

107. Safarinejad MR. Evaluation of the safety and efficacy of sildenafil citrate for erectile dysfunction in men with multiple sclerosis: a double-blind, placebo controlled, randomized study. J Urol. 2009; 181:252-258.

108. Lombardi G, Macchiarella A, Del Popolo G. Efficacy and safety of tadalafil for erectile dysfunction in patients with multiple sclerosis. J Sex Med. 2010; 7:2192-2200.

109. Vidal J, Curcoll L, Roig T, Bagunyá J. Intracavernous pharmacotherapy for management of erectile dysfunction in multiple sclerosis patients. Rev Neurol. 1995; 23:269-271.

110. Kirkeby HJ, Petersen T, Poulsen EU. Pharmacologically induced erection in patients with multiple sclerosis. Scand J Urol Nephrol. 1988; 22:241-244.

111. Hirsch IH, Smith RL, Chancellor MB, et al. Use of intracavernous injection of prostaglandin E1 for neuropathic erectile dysfunction. Paraplegia. 1994; 32:661-664.

112. Foley FW, LaRocca NG, Sanders AS, Zemon V. Rehabilitation of intimacy and sexual dysfunction in couples with multiple sclerosis. Mult Scler. 2001; 7:417-421.

113. Rathore C, Henning OJ, Luef G, Radhakrishnan K. Sexual dysfunction in people with epilepsy. Epilepsy Behav. 2019; 100:106495.

114. Montouris G, Morris GL $3^{\text {rd }}$. Reproductive and sexual dysfunction in men with epilepsy. Epilepsy Behav. 2005; 7 (Suppl 2):S7-S14.

115. Smaldone M, Sukkarieh T, Reda A, Khan A. Epilepsy and erectile dysfunction: a review. Seizure. 2004; 13:453-459.

116. Daniele A, Azzoni A, Bizzi A, et al. Sexual behavior and hemispheric laterality of the focus in patients with temporal lobe epilepsy. Biol Psychiatry. 1997; 42:617-624.

117. Harden CL. Sexuality in men and women with epilepsy. CNS Spectr. 2006; 11 (8 Suppl 9):13-18.

118. Bauer J, Stoffel-Wagner B, Flügel D, et al. Serum androgens return to normal after temporal lobe epilepsy surgery in men. Neurology. 2000; 55:820-824.

119. Spark RF, Wills CA, Royal H. Hypogonadism, hyperprolactinaemia, and temporal lobe epilepsy in hyposexual men. Lancet. 1984; 1 (8374):413-417.

120. Najafi MR, Ansari B, Zare M, et al. Effects of antiepileptic drugs on sexual function and reproductive hormones of male epileptic patients. Iran J Neurol. 2012; 11:37-41.

121. Yogarajah M, Mula M. Sexual dysfunction in epilepsy and the role of anti-epileptic drugs. Curr Pharm Des. 2017; 23:5649-5661.

122. Yogarajah M, Mula M. Sexual dysfunction in epilepsy and the role of anti-epileptic drugs. Curr Pharm Des. 2017; 23:5649-5661.

123. Sachdeo R, Sathyan RR. Amelioration of erectile dysfunction following a switch from carbamazepine to oxcarbazepine: recent clinical experience. Curr Med Res Opin. 2005; 21:1065-1068.

124. Alhathal N, Elshal AM, Carrier S. Synergetic effect of testosterone and phophodiesterase-5 inhibitors in hypogonadal men with erectile dysfunction: A systematic review. Can Urol Assoc J. 2012; 6:269-274

125. Talbot JA, Sheldrick R, Caswell H, Duncan S. Sexual function in men with epilepsy: how important is testosterone? Neurology. 2008; 70:1346-1352.
126. Bóné B, Janszky J. Az epilepszia es a férfi nemi muködes zavara: okok, diagnózis es terápia [Epilepsy and male sexual dysfunction: etiology, diagnosis and therapy]. Ideggyogy Sz. 2006; 59:148-152.

127. Matos G, Scorza FA, Cavalheiro EA, et al. PDEI-5 for erectile dysfunction: a potential role in seizure susceptibility. J Sex Med. 2012; 9:2111-2121

128. Riazi K, Roshanpour M, Rafiei-Tabatabaei N, et al. The proconvulsant effect of sildenafil in mice: role of nitric oxide-cGMP pathway. Br J Pharmacol. 2006; 147:935-943.

129. Socała K, Nieoczym D, Pieróg M, et al. Effect of tadalafil on seizure threshold and activity of antiepileptic drugs in three acute seizure tests in mice. Neurotox Res. 2018; 34:333-346.

130. Braun M, Sommer F, Lehmacher W, et al. Erectile dysfunction. Are interdisciplinary diagnosis and therapy necessary?. Dtsch Med Wochenschr. 2004; 129:131-6.

131. Akbas NB, Dalbayrak S, Külcü DG, et al. Assessment of sexual dysfunction before and after surgery for lumbar disc herniation. J Neurosurg Spine. 2010; 13:581-6.

132. Kanayama M, Horio M, Umi Y, et al. How does surgery affect sexual desire and activities in patients with lumbar disc herniation? Spine 2010; 35:647-51.

133. Yazici CM, Sarifakioglu B, Guzelant A, et al. An unresolved discussion: presence of premature ejaculation and erectile dysfunction in lumbar disc hernia. Int Urol Nephrol. 2013 ; 45:659-67.

134. Akca N, Ozdemir B, Kanat A, et al. Describing a new syndrome in L5-S1 disc herniation: Sexual and sphincter dysfunction without pain and muscle weakness. J Craniovertebr Junction Spine. 2014; 5:146-150.

135. Xu HD, Zhao JN, Xu B, et al. Penile erectile function after lumbar discectomy for intervertebral disc herniation in different age groups of male patients. Zhonghua Nan Ke Xue. 2013; 19:626-9.

136. Dzierzanowski $M$, Dzierzanowski $M$, Wrzecion $K$, et al. Discopathy of the lumbar-sacral segment and its influence on sexual dysfunction. Adv Clin Exp Med. 2013; 22:93-100.

137. Podnar S, Oblak C, Vodusek DB. Sexual function in men with cauda equina lesions: a clinical and electromyographic study. J Neurol Neurosurg Psychiatry. 2002; 73:715-720.

138. DS. Early relief of erectile dysfunction after laser decompression of herniated lumbar disc. J Clin Laser Med Surg. 1999; 17:257 .

139. Orlin JR, Klevmark B. Successful disc surgery after 17 years of erectile dysfunction caused by a "silent" disc protrusion. Scand J Urol Nephrol. 2008; 42:91-3.

140. Kulaksizoglu H, Kaptan H. An unappreciated correlation: surgical treatment of lumbosacral disc disease and erectile dysfunction. J Korean Neurosurg Soc. 2010; 47:282-6.

141. Stefanova N, Bücke P, Duerr S, Wenning GK. Multiple system atrophy: an update. Lancet Neurol. 2009; 8:1172-8.

142. Kirchhof K, Apostolidis AN, Mathias CJ, Fowler CJ. Erectile and urinary dysfunction may be the presenting features in patients with multiple system atrophy: a retrospective study. Int J Impot Res. 2003; 15:293-8.

143. Papatsoris AG, Papapetropoulos S, Singer C, Deliveliotis C. Urinary and erectile dysfunction in multiple system atrophy (MSA). Neurourol Urodyn. 2008; 27:22-7.

144. Palma JA, Kaufmann H. Treatment of autonomic dysfunction in Parkinson disease and other synucleinopathies. Mov Disord. 2018; 33: 372-390. 
145. Podnar S, Vodušek DB. Sexual dysfunction in patients with peripheral nervous system lesions. Handb Clin Neurol. 2015; 130:179-202.

146. Furukawa S, Sakai T, Niiya T, et al. Diabetic peripheral neuropathy and prevalence of erectile dysfunction in Japanese patients aged < 65 years with type 2 diabetes mellitus: The Dogo Study. Int J Impot Res. 2017; 29:30-34.

147. Maiorino MI, Bellastella G, Esposito K. Diabetes and sexual dysfunction: current perspectives. Diabetes Metab Syndr Obes. 2014; 7:95-105.

148. Benvenuti F, Boncinelli L, Vignoli GC. Male sexual impotence in diabetes mellitus: vasculogenic versus neurogenic factors. Neurourol Urodyn. 1993; 12:145-51

149. Hecht MJ, Neundörfer B, Kiesewetter F, Hilz MJ. Neuropathy is a major contributing factor to diabetic erectile dysfunction. Neurol Res. 2001; 23:651-4.

150. Cellek S, Cameron NE, Cotter MA, Muneer A. Pathophysiology of diabetic erectile dysfunction: potential contribution of vasa nervorum and advanced glycation endproducts. Int J Impot Res. 2013; 25:1-6.

151. Tamás V, Kempler P. Sexual dysfunction in diabetes. Handb Clin Neurol. 2014; 126:223-32.

152. Yoshimura N, Kato R, Chancellor MB, et al. Gene therapy as future treatment of erectile dysfunction. Expert Opin Biol Ther. 2010; 10:1305-1314.

153. Burnett AL. Erectile function outcomes in the current era of anatomic nerve-sparing radical prostatectomy. Rev Urol. 2006; 8:47-53.

154. Padma-Nathan H, McCullough A, Forest C. Erectile dysfunction secondary to nerve-sparing radical retropubic prostatectomy: comparative phosphodiesterase-5 inhibitor efficacy for therapy and novel prevention strategies. Curr Urol Rep. 2004; 5:467-71.

155. Capogrosso P, Salonia A, Briganti A, Montorsi F. Postprostatectomy erectile dysfunction: a review. World J Mens Health. 2016; 34:73-88.

\section{Correspondence}

Mohamad Moussa, MD

mohamadamoussa@hotmail.com

Head of Urology Department, Zahraa Hospital, University Medical

Center, Beirut (Lebanon)

Athanasios G. Papatsoris, MD (Corresponding Author)

agpapatsoris@yahoo.gr

$2^{\text {nd }}$ Department of Urology, School of Medicine, Sismanoglio Hospital,

National and Kapodistrian University of Athens, Athens (Greece)

Mohamed Abou Chakra, MD

mohamedabouchakra@hotmail.com

Department of Urology, Faculty of Medical Sciences, Lebanese University,

Beirut (Lebanon)

Baraa Dabboucy, MD

baraa.dabboucy@gmail.com

Department of Neurosurgery, Faculty of Medical Sciences, Lebanese

University, Beirut (Lebanon)

Youssef Fares, MD

yfares@ul.edu.lb

Department of Neurosurgery, Neuroscience Research Center, Faculty

of Medical Sciences, Lebanese University, Beirut (Lebanon) 